\title{
Marchi, Riccardo (2020), A nova direita anti-sistema: o caso do Chega
}

Rahul Kumar

\section{OpenEdition}

Journals

Edição electrónica

URL: https://journals.openedition.org/rccs/12314

DOI: $10.4000 /$ rccs. 12314

ISSN: 2182-7435

Editora

Centro de Estudos Sociais da Universidade de Coimbra

\section{Edição impressa}

Data de publição: 1 setembro 2021

Paginação: 185-187

ISSN: 0254-1106

\section{Refêrencia eletrónica}

Rahul Kumar, «Marchi, Riccardo (2020), A nova direita anti-sistema: o caso do Chega», Revista Crítica de Ciências Sociais [Online], 125 | 2021, publicado a 30 setembro 2021, consultado a 03 outubro 2021. URL: http://journals.openedition.org/rccs/12314 ; DOI: https://doi.org/10.4000/rccs.12314 


\section{RECENSÕES}

\section{Marchi, Riccardo (2020), A nova direita anti-sistema: o caso do Chega. Lisboa: Edições 70, 206 pp.*}

A figura de André Ventura e a trajectória do partido Chega têm suscitado um intenso debate sobre o crescimento da extrema-direita e as transformações no sistema partidário português. Inserido num movimento editorial internacional que tem procurado compreender as metamorfoses contemporâneas e a radicalização da direita - e encontrar um nome para a coisa - o livro de Riccardo Marchi constitui o primeiro trabalho académico sobre a variação portuguesa deste processo global. O problema que organiza a investigação é justamente o da classificação do partido, ou seja, como é que "o partido Chega encaixa nos conceitos que lhe são reservados por jornalistas e analistas políticos - populismo de direita, direita radical, extrema-direita, etc. - e em que medida representa uma inovação na reconfiguração da direita portuguesa” (p. 5). Este problema é explorado por Marchi a partir de três dimensões de análise que dão o título a cada um dos capítulos do livro - "O líder", "O partido" e "As ideias" - e apoia-se em três tipos de fontes e materiais empíricos: os documentos programáticos do partido, uma pequena recolha de imprensa e 21 entrevistas realizadas a membros do partido.

O Chega, não obstante o título do livro, é definido nas conclusões como um "partido populista da nova direita radical” (p. 191). Esta classificação resulta de um compósito entre duas dicotomias conceptuais: extrema-direita vs. direita radical e velha direita vs. nova direita. O Chega é, de acordo com
Marchi, um partido da nova direita radical porque aceita as regras do jogo democrático (ao contrário da extrema-direita) e não se reconhece no legado dos regimes autoritários do período entreguerras (ao contrário da velha direita). O Chega é ainda um partido populista porque "a sua mundividência está baseada numa perspectiva dicotómica da realidade política, segundo a qual, há 45 anos, uma elite se apoderou dos gânglios do poder político, económico, mediático e cultural, atraiçoando o povo português, mantido, cada vez mais, na margem de qualquer processo decisório e vexado nas suas componentes mais produtivas" (p. 193). Em cada um dos capítulos o autor procura acrescentar ao problema taxonómico dois argumentos auxiliares: 1) "o Chega não pertence à linha genealógica da direita radical portuguesa"; 2) "é algo inédito na democracia portuguesa, do ponto de vista quer da cultura política reivindicada, quer da estratégia discursiva eleita, quer da polimorfia dos quadros fundadores e da base de apoio" (p. 14).

O Chega, visto por Marchi, é um projecto pessoal de André Ventura. Sem apoios, e sem ligações às elites económicas, políticas e culturais do país, "André Ventura sai do PSD com uma mão cheia de nada e outra de coisa nenhuma" (p. 20). Para o autor, a experiência pessoal de Ventura, filho da pequena burguesia dos subúrbios lisboetas, permite-lhe representar as ideias até aqui silenciadas e as preocupações até

* Por vontade do autor, este texto não segue as regras do Acordo Ortográfico de 1990. 
aqui ignoradas de um eleitorado cada vez mais afastado da direita tradicional. Este novo partido "substancialmente integrado na mundividência portuguesa, e não apenas de direita” (p. 135), focado nas variáveis nacionais "e não na reprodução de modelos estrangeiros, nomeadamente dos populismos de direita europeus e americanos, de que será constantemente acusado" (p. 51), cresce em função da ambição e do esforço de Ventura e de um pequeno grupo de amigos, coleccionados ao longo da sua vida. A ampliação deste núcleo restrito deu-se nas redes sociais. $\mathrm{O}$ recrutamento nas redes sociais foi, segundo Marchi, a estratégia eleita para contornar a ausência de recursos materiais e a estigmatização de que o partido sempre foi alvo nos meios de comunicação social. É também a possibilidade de recurso às redes sociais que distingue o Chega de outros projectos políticos anteriores do mesmo quadro ideológico. Trata-se exactamente da mesma razão pela qual Ventura se multiplica em declarações controversas: para "maximizar o seu instinto polémico em temas fracturantes da sociedade” (p. 47), para prosseguir uma estratégia de diferenciação política com vista à aproximação de segmentos eleitorais específicos das cinturas metropolitanas e para furar o "bloqueio mediático" ao partido (p. 63). Organizado ideologicamente em torno do liberalismo económico e do conservadorismo nos valores, as "indefinições" do Chega em relação a uma série de temas, desde as funções sociais do Estado até à integração europeia, resultam, para o autor, da ausência de uma "doutrina monolítica" e "da pluralidade das fontes de produção e das culturas políticas dos militantes" (p. 135).

As diversas leituras críticas publicadas na imprensa nas semanas seguintes à edição do livro, no final de Junho de 2020, revelaram de forma clara - e quase sempre justa - uma série de lacunas, erros, omissões e incongruências no trabalho de pesquisa de Riccardo Marchi. No essencial, essas críticas remetem para duas questões inter-relacionadas: o problema da classificação do partido e do modelo analítico e metodológico utilizado pelo autor. Considerando esta última dimensão, e acrescentando alguns elementos às análises já realizadas, é possível elencar um vasto conjunto de deficiências: ausência de um quadro conceptual e analítico claro (o debate sobre o conceito de populismo, por exemplo, é resolvido na conclusão em 14 linhas); inexistência de uma bibliografia ou mesmo de referenciação de autores citados; desvalorização de uma abordagem comparativa internacional (com partidos congéneres) ou mesmo nacional (relação entre as diferentes direitas); fragilidade do enquadramento histórico (falta de referência às transformações do sistema partidário nacional ou ao comportamento eleitoral e às atitudes políticas dos portugueses); desvalorização da conjuntura política (polarização e fragmentação dos sistemas partidários ou intensificação dos debates sobre os legados autoritários e coloniais); selecção enviesada dos materiais empíricos e erros no seu tratamento (muito longe da saturação das fontes, sem análise cruzada de dados, sem clarificação dos critérios amostrais e sem explicitação dos termos de acesso ao terreno); e, talvez mais grave, a total indiferenciação entre as categorias analíticas e as categorias nativas. Assim, e como foi também sublinhado em várias críticas, a voz de Marchi e a voz dos seus interlocutores confundem-se sistematicamente ao longo do argumento, sendo os pontos de vista dos seus informadores tratados quase sempre como factos, lidos de forma não-problemática, ao passo que as perspectivas antagónicas ora são ignoradas ora são descredibilizadas.

Das várias fragilidades metodológicas e analíticas do trabalho, e cujas razões merecem seguramente uma reflexão muito mais aprofundada, resulta um retrato incongruente 
e contraditório do partido. O problema taxonómico, o segundo ponto crítico do livro e que espoletou o debate público, contribui então para obscurecer ainda mais algumas das questões que o crescimento do Chega coloca à história das direitas portuguesas. $\mathrm{Na}$ realidade, se alguma coisa o trabalho de Marchi demonstra é a necessidade de uma análise processual e relacional ao percurso do Chega: uma investigação que vá para além do problema da categorização, que não se limite ao discurso oficial do partido e que revele as trajectórias sociais, políticas e ideológicas dos seus quadros, militantes e eleitores. $\mathrm{Na}$ tentativa de mostrar que o Chega não é um partido de extrema-direita, e de colocar os diferentes partidos e actores da direita numa grelha classificatória fechada, Marchi não explora as ligações entre o partido de Ventura e as direitas tradicionais portuguesas no que diz respeito - e para voltar às teses do autor - à cultura política reivindicada, à estratégia discursiva eleita, à polimorfia dos quadros e à sua base de apoio.

Poucas vezes uma tese começa a desmentir-se a si própria na epígrafe. Mas é justamente isso que aqui sucede, ao abrir com uma citação de Jaime Nogueira Pinto (a principal figura daquilo que se poderia chamar a velha nova direita portuguesa), na segunda convenção do Movimento Europa e Liberdade, que juntou, em Março de 2020, os diferentes sectores das direitas portuguesas num debate colectivo. As referências fundamentais de Ventura - "na encruzilhada entre a doutrina da Igreja, o pensamento de Francisco Sá Carneiro, e a leitura das obras de Jaime Nogueira Pinto, em particular o seu O Fim do Estado Novo e as Origens do 25 de Abril" (p. 23) -, as trajectórias dos seus principais quadros - quase todos provenientes do CDS e/ou do PSD, como o próprio Ventura - bastariam para traçar a filiação do Chega nas direitas com representação parlamentar. Se a isso juntarmos as heranças ideológicas materializadas nas propostas políticas do partido (liberalismo na economia e conservadorismo nos valores); as coligações sociais que o partido procura construir com diferentes sectores do empresariado português e dos conservadores religiosos; e a representação de um eleitorado específico - "a direita clássica do mundo rural e das elites mais conservadoras; as bases populares do interior do país; os subúrbios das grandes cidades" (p. 49) - é impossível pensar a emergência de uma extrema-direita em Portugal sem repensar a história da direita portuguesa como um todo. Em suma, a tese de Marchi sobre o Chega, sintetizada no título do livro $A$ nova direita anti-sistema, tem dois problemas: esta direita não é nova nem é anti-sistema.

Rabul Kumar

Revisto por Alina Timóteo

\section{Rahul Kumar}

Faculdade de Economia, Universidade de Coimbra I Instituto de História Contemporânea, Faculdade de Ciências Sociais e Humanas, Universidade NOVA de Lisboa

Av. Dias da Silva, 165, 3004-512 Coimbra, Portugal

Contacto: rahul.m.kumar@gmail.com

ORCID: https://orcid.org/0000-0003-4799-149X

https://doi.org/10.4000/rccs.12314 